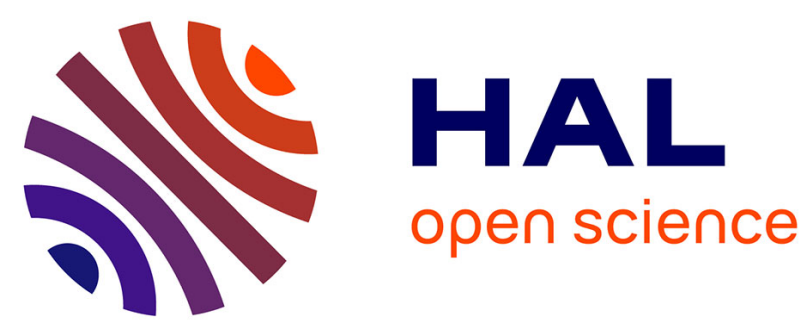

\title{
Frequency-tunable slot-loop antenna based on KNN ferroelectric interdigitated varactors
}

Barthelemy Aspe, Xavier Castel, Valérie Demange, Stéphanie Députier, Valerie Bouquet, Ratiba Benzerga, Ronan Sauleau, Maryline Guilloux-Viry

\section{- To cite this version:}

Barthelemy Aspe, Xavier Castel, Valérie Demange, Stéphanie Députier, Valerie Bouquet, et al.. Frequency-tunable slot-loop antenna based on KNN ferroelectric interdigitated varactors. IEEE Antennas and Wireless Propagation Letters, 2021, 20 (8), pp.1414-1418. 10.1109/LAWP.2021.3084320 . hal-03242826

\section{HAL Id: hal-03242826 \\ https://hal.science/hal-03242826}

Submitted on 16 Jun 2021

HAL is a multi-disciplinary open access archive for the deposit and dissemination of scientific research documents, whether they are published or not. The documents may come from teaching and research institutions in France or abroad, or from public or private research centers.
L'archive ouverte pluridisciplinaire HAL, est destinée au dépôt et à la diffusion de documents scientifiques de niveau recherche, publiés ou non, émanant des établissements d'enseignement et de recherche français ou étrangers, des laboratoires publics ou privés. 


\title{
Frequency-Tunable Slot-Loop Antenna based on KNN Ferroelectric Interdigitated Varactors
}

\author{
Barthélemy Aspe, Xavier Castel, Valérie Demange, Stéphanie Députier, Valérie Bouquet, Ratiba \\ Benzerga, Ronan Sauleau, Fellow, IEEE, and Maryline Guilloux-Viry
}

\begin{abstract}
A miniature frequency-tunable slot-loop antenna $\left(0.128 \lambda_{0} \times 0.077 \lambda_{0}\right)$ based on ferroelectric $\mathrm{K}_{0.5} \mathrm{Na}_{0.5} \mathrm{NbO}_{3}(\mathrm{KNN})$ interdigitated varactors is investigated at Ku-band. KNN material has been selected among the ferroelectric oxide family because of its competitive properties for microwave applications. Its high permittivity value $(\varepsilon \approx 360$ at $10 \mathrm{GHz})$ and its wide frequency tunability under an external static electric field $\boldsymbol{E}_{\text {bias }}$ make it a promising candidate for frequency-agile antennas and circuits at microwaves. The antenna prototype has been designed and elaborated on $\mathrm{MgO}$ substrate $\left(\varepsilon_{r}=9.8\right.$ and $\tan \delta \approx 10^{-4}$ at $\left.10 \mathrm{GHz}\right)$. Fabrication details including laser microetching process of the ferroelectric layer are also described. The center frequency of the slot-loop antenna can therefore be tuned monotonously from 15.22 to $15.97 \mathrm{GHz}$ under $E_{\text {bias }}=88 \mathrm{kV} / \mathrm{cm}$, leading to a frequency tunability rate equal to $4.6 \%$. These results demonstrate for the first time the ability of the KNN material to be used for miniature tunable antennas, in comparison with $\mathrm{Ba}_{x} \mathrm{Sr}_{1-x} \mathrm{TiO}_{3}$, currently considered as the most relevant material for such applications.
\end{abstract}

Index Terms - Ferroelectric films, Microwave devices, Slot Antennas, Tunable devices, Varactors.

\section{INTRODUCTION}

$\mathrm{N}^{2}$ owadays, the intensive use of connected objects creates a growing demand for miniaturization in electronics. In this competitive environment, tunable antennas promote attractive solutions for multi-standard and/or adaptive wireless systems. Among the technical solutions available to achieve frequency tunability, ferroelectric thin films exhibit numerous advantages. Indeed, they exhibit low energy consumption, fast response times (lower than $1 \mu \mathrm{s}$ ), and enable a monotonous tuning of devices. Moreover, the films can be implemented fairly easily in tunable capacitors (varactors), based on microstrip interdigital capacitor (IDC) or metal-insulator-metal (MIM) technologies. Furthermore, their intrinsic high permittivity value is a key advantage for device miniaturization. Therefore, this technology is a promising solution for cost and size reductions of tunable microwave devices [1]-[3]. The

The authors are grateful for the financial support of the Direction Générale de l'Armement (DGA) and the Région Bretagne (PhD research Grant of B. Aspe project ARMin). This work was also supported by the European Union through the European Regional Development Fund (ERDF), the Ministry of Higher Education and Research, the Région Bretagne, the Conseil Départemental des Côtes d'Armor, the Conseil Départemental d'Ille et Vilaine, and Saint-Brieuc Armor Agglomération, through the CPER Projects 2015-2020 MATECOM and SOPHIE / STIC \& Ondes. ScanMAT, UMS 2001 CNRSUniversity of Rennes 1, received a financial support from Rennes Métropole, the Région Bretagne, the Conseil Départemental d'Ille et Vilaine and the European Union (CPER-FEDER 2007-2014, CPER SCANMAT 2015-2020). investigation of various ferroelectric materials, in particular among the lead-free oxides, is a key issue to identify the best candidates to lead to performant tunable antennas. Taking into account all the steps of the design, fabrication and measurements of the antenna is very important to achieve a relevant evaluation of the materials for further use.

Ferroelectric materials have been investigated at microwaves for tunable phase shifters (e.g. [4]), tunable filters (e.g. [5]) and tunable antennas (e.g. [6]). Most of these studies are based on $\mathrm{Ba}_{\mathrm{x}} \mathrm{Sr}_{1-\mathrm{x}} \mathrm{TiO}_{3}$ (BST) materials due to its composition-dependent dielectric characteristics and its low loss tangent value (tan $\delta$ lower than 0.03 at $20 \mathrm{GHz}$ on thin films [7]). Among the examples, in 2012, H.-Y. Li et al. introduced a slot-loop miniature tunable antenna with BST-based interdigitated varactors and operating close to $15 \mathrm{GHz}$ [8]; such antenna exhibited a $1 \%$-frequency tunability rate under $195 \mathrm{kV} / \mathrm{cm} \mathrm{dc}$ bias electric field. To increase the tunability rate, this group proposed slot-loop miniature tunable antennas based on MIM varactors operating at $C$ - and $X$-bands [9], [10]. MIM capacitors have been often exploited [9]-[13] as this configuration helps to increase the applied external static electric field, thus leading to an increase of the tunability rate up to $27.3 \%$ and $30.6 \%$, respectively (Table I). However, these antennas usually suffered from very low gain values and such MIM capacitors are really challenging to fabricate. Other details from miniature antenna structures using ferroelectric-based varactors are also reported in Table I.

Even though BST material is usually considered as one of the most relevant ferroelectric oxide for microwave applications, alternative materials are currently under investigation, such as $\mathrm{AgTa}_{1-\mathrm{x}} \mathrm{Nb}_{\mathrm{x}} \mathrm{O}_{3}$ [14], $\mathrm{Sr}_{1-\mathrm{x}} \mathrm{Bi}_{\mathrm{x}} \mathrm{TiO}_{3}$ [15], $\mathrm{BaZr}_{\mathrm{x}} \mathrm{Ti}_{1-\mathrm{x}} \mathrm{O}_{3}$ [16], $\mathrm{PbZr}_{\mathrm{x}} \mathrm{Ti}_{1-\mathrm{x}} \mathrm{O}_{3}$ [17] and $\mathrm{KTa}_{\mathrm{x}} \mathrm{Nb}_{1-\mathrm{x}} \mathrm{O}_{3}$ [18]. A tunable antenna based on $\mathrm{KTa}_{\mathrm{x}} \mathrm{Nb}_{1-\mathrm{x}} \mathrm{O}_{3}(\mathrm{KTN})$ films was proposed in [19], [20]. It exhibited a maximum gain value equal to $6.7 \mathrm{dBi}$ and $1.7 \%$ frequency tunability rate under $85 \mathrm{kV} / \mathrm{cm}$ dc bias electric field.

B. Aspe was with the Univ Rennes, CNRS, ISCR UMR 6226, ScanMAT UMS 2001 and IETR UMR 6164, F-35000 Rennes, France. He is currently with the Luxembourg Institute of Science and Technology, L-4422 Belvaux, Luxembourg (e-mail: barthelemy.aspe@list.lu). V. Demange, S. Députier, V. Bouquet, and M. Guilloux-Viry are with the Univ Rennes, CNRS, ISCR UMR 6226, ScanMAT UMS 2001, F-35000 Rennes, France (e-mails: valerie.demange@univ-rennes1.fr, stephanie.deputier@univ-rennes1.fr, valerie.bouquet@univ-rennes1.fr, maryline.guillloux-viry@univ-rennes1.fr). X. Castel, R. Benzerga and R. Sauleau are with the Univ Rennes, CNRS, IETR UMR 6164, F-35000 Rennes, France (e-mails: xavier.castel@univ-rennes1.fr, ratiba.benzerga@univ-rennes1.fr, ronan.sauleau@univ-rennes1.fr). 
TABLE I

MINIATURE AND TUNABLE ANTENNAS BASED ON PRINTED FERROELECTRIC VARACTORS

\begin{tabular}{|c|c|c|c|c|c|c|c|c|}
\hline Reference & [12] & [13] & [11] & [8] & [9] & [10] & {$[19],[20]$} & This work \\
\hline Substrate & Sapphire & Sapphire & Sapphire & Sapphire & Sapphire & Sapphire & Sapphire & $\mathrm{MgO}$ \\
\hline Ferroelectric material & BST & BST & BST & BST & BST & BST & KTN & KNN \\
\hline Film thickness (nm) & 250 & 250 & 250 & 200 & 200 & 170 & 600 & 600 \\
\hline Varactor technology & MIM & MIM & MIM & IDC & MIM & MIM & CPW & IDC \\
\hline$E_{\text {bias_max }}(\mathbf{k V / c m})^{*}$ & 120 & 280 & 400 & 195 & 350 & 880 & 85 & 88 \\
\hline Frequency range $(\mathbf{G H z})^{* *}$ & $5.8-6.1$ & $5.28-5.77$ & $7.42-7.9$ & $15.18-15.36$ & $5.57-7.33$ & $6.71-9.14$ & $17.0-17.3$ & $15.22-15.97$ \\
\hline Tunability rate $(\%)$ & 5 & 8.9 & 6.3 & 1.2 & 27.3 & 30.6 & 1.7 & 4.6 \\
\hline
\end{tabular}

* As mentioned or computed from the available paper data

** Measured frequencies at minimal $\left|S_{11}\right|$ without and under $E_{\text {bias } \max }$

Another alternative to BST material lies in the perovskite-type $\mathrm{K}_{0.5} \mathrm{Na}_{0.5} \mathrm{NbO}_{3}(\mathrm{KNN})$ oxide. The $\mathrm{KNN}$ system is most famous for its piezoelectric properties, since Saito et al. reported high piezoelectric modulus values $\left(d_{33} \approx 300 \mathrm{pC} / \mathrm{N}\right.$ [21]) with a Curie temperature close to $400^{\circ} \mathrm{C}$ [22], making it a promising alternative to the widely used $\mathrm{PbZrTiO}_{3}$ material. In addition, recent studies have also demonstrated interesting $\mathrm{KNN}$ thin films properties at microwaves with a high dielectric constant $\left(\varepsilon_{r} \approx 360\right.$ at $10 \mathrm{GHz}$ and $22 \%$-frequency tunability under $94 \mathrm{kV} / \mathrm{cm}$ dc bias electric field [23], [24]).

In the present work, a frequency-tunable slot-loop antenna was designed, fabricated and measured using KNN film-based microstrip IDC varactors. Although previous works have demonstrated the relevance of ferroelectric varactors for miniaturization and reconfigurability (e.g. [10], [13]), the present study reports, for the first time to the best of our knowledge, the use of KNN material for frequency-tunable antenna application. The paper is organized as follows. Design, fabrication and measurement procedures are described in Section II. Numerical and measured results are presented, compared and discussed in Section III. Conclusions are drawn in Section IV

\section{ANTENNA DESIGN, FABRICATION, AND MEASUREMENT PROCEDURES}

\section{A. Antenna design}

The proposed antenna is a $2.5 \mathrm{~mm} \times 1.5 \mathrm{~mm}$ slot-loop antenna fabricated on a $600 \mathrm{~nm}$-thick KNN thin film grown on $10 \mathrm{~mm} \times 10 \mathrm{~mm} \times 0.5 \mathrm{~mm} \mathrm{MgO}$ substrate $\left(\varepsilon_{r}=9.8\right.$ and $\tan \delta \approx 10^{-4}$ at $10 \mathrm{GHz}$ and room temperature). The antenna was designed to operate at $K u$-band. Its layout (inspired from [8], [9]) and cross-section view are reported in Fig. 1a and $1 \mathrm{~b}$ respectively. The antenna dimensions are detailed in Table II. The slot loop (width $G=50 \mu \mathrm{m}$ ) is fed through a $50-\Omega$ coplanar waveguide (CPW) transmission line ( $w=100 \mu \mathrm{m}, g=300 \mu \mathrm{m})$. Interdigitated varactors are symmetrically placed in the upper and lower slots to tune the antenna operating frequency. The antenna is polarized through an external dc voltage from $0 \mathrm{~V}$ to
$150 \mathrm{~V}$. As the gap $G_{c}$ between the capacitor fingers is $15 \mu \mathrm{m}$ in width, the maximum applied dc voltage leads to a maximum external static electric field $E_{\text {bias }}=100 \mathrm{kV} / \mathrm{cm}$, a significantly low value compared with those reported in Table I (except for [19], [20]). The main dielectric characteristics of the KNN film used for the antenna design are: $\varepsilon_{r}=355$ and $\tan \delta=0.35$ without biasing; $\varepsilon_{r}=315$ and $\tan \delta=0.30$ under $E_{\text {bias }}=27 \mathrm{kV} / \mathrm{cm}$ (the maximum $E_{\text {bias }}$ value applied on the transmission lines used to retrieve the $\left(\varepsilon_{r} ; \tan \delta\right)$ dielectric characteristics of the KNN film at $10 \mathrm{GHz}$ [23], [24]). The antenna dimensions, the placement and numbers of varactors were optimized using Ansys HFSS v18.0; the fabrication constraints have also been taken into account, as explained below.

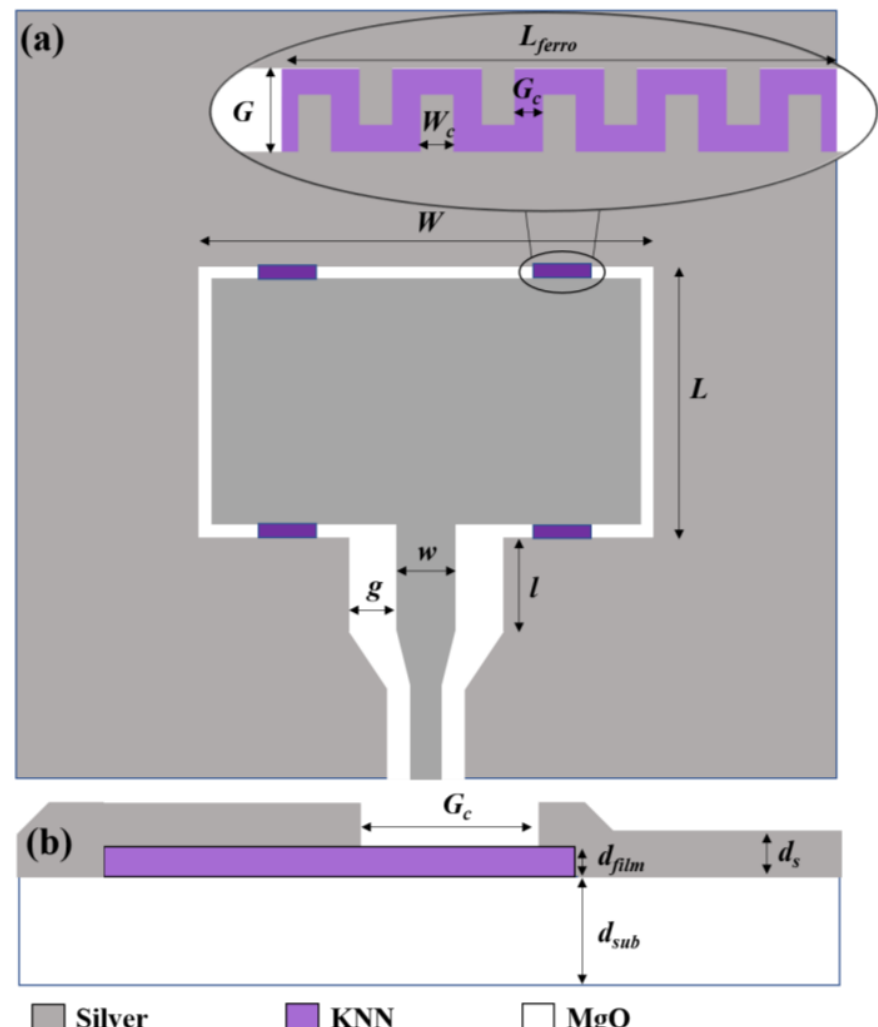

Fig. 1. (a) Layout (top view) and (b) cross-section of the frequency-tunable IDC varactor (not-to-scale).

TABLE II

DIMENSIONS OF THE FREQUENCY-TUNABLE SLOT-LOOP ANTENNA

\begin{tabular}{ccccccccccccc}
\hline \hline Symbol & $L$ & $W$ & $G$ & $l$ & $w$ & $g$ & $L_{\text {ferro }}$ & $W_{c}$ & $G_{c}$ & $d_{\text {sub }}$ & $d_{s}$ & $d_{\text {flm }}$ \\
Length $(\mu \mathrm{m})$ & 1500 & 2500 & 50 & 2500 & 100 & 300 & 320 & 20 & 15 & 500 & 2 & 0.6 \\
\hline
\end{tabular}




\section{B. Antenna fabrication}

The manufacturing process of the antenna prototype is the following. First a $600 \mathrm{~nm}$-thick ferroelectric film was grown by pulsed laser deposition on a (100) $\mathrm{MgO}$ substrate, using a $\mathrm{KrF}$ excimer laser (Coherent company, pulse duration: $20 \mathrm{~ns}, \lambda=$ $248 \mathrm{~nm}$ ) with an energy of $210 \mathrm{~mJ}$, a fluence of $2-3 \mathrm{~J} . \mathrm{cm}^{-2}$ and a working frequency of $4 \mathrm{~Hz}$ to ablate the ceramic KNN target. The film was deposited at $650^{\circ} \mathrm{C}$ under 0.3 -mbar oxygen pressure. (100) $\mathrm{MgO}$ substrate was selected here because of (i) its suitable dielectric characteristics at microwaves, and (ii) the low mismatch between its crystalline parameters and those of the KNN film, promoting a high structural ferroelectric layer quality enhancing the frequency tunability [24]. X-ray diffraction showed a (100)-oriented single phase KNN perovskite film. As expected, the KNN films exhibited epitaxial relationships with the (100) $\mathrm{MgO}$ single crystal substrate [24]. Further details on the laser deposition process and the structural properties of the ferroelectric thin film are reported in [23], [24].

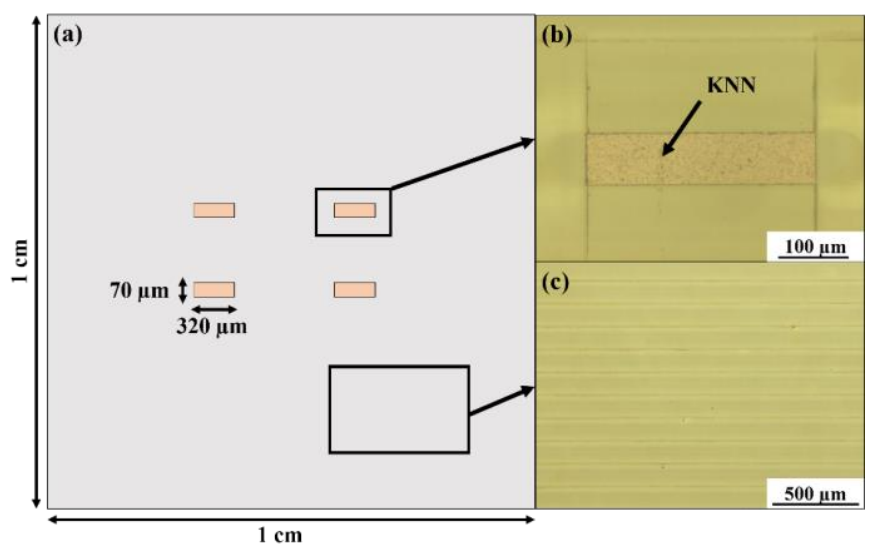

Fig. 2. (a) Schematic representation (not-to-scale) and (b), (c) pictures (optical microscopy) of a KNN strip and of a $\mathrm{KNN}$-free substrate after laser microetching, respectively.

Afterwards, the KNN film was locally ablated by laser microetching process to keep only four $320 \mu \mathrm{m} \times 70 \mu \mathrm{m} \mathrm{KNN}$ areas on which the interdigital capacitors were printed (Fig. 2). This route allows reducing the global loss of antenna because the ferroelectric materials usually exhibit relatively high dielectric loss (their loss tangent tan $\delta$ is typically higher than $1 \%$ ). As previously demonstrated, the global loss was reduced by a factor four by confining the ferroelectric layer into the active areas [25]. To this end, a KrF excimer laser (MLI-200, MLaser, $\lambda=248 \mathrm{~nm}$ ) was used to etch the $600 \mathrm{~nm}$-thick KNN layer with a $150 \mu \mathrm{m} \times 150 \mu \mathrm{m}$ laser spot size and an energy of $3 \mathrm{~mJ}$ reduced of $45 \%$ through an optical filter. The parameters and etching pattern were set by OptecCAD and Process Power software tools. The slot-loop antenna was then printed on such layer from a $2 \mu \mathrm{m}$-thick silver overlayer / $5 \mathrm{~nm}$-thick titanium underlayer deposited by RF magnetron sputtering. Therefore, the silver thickness is three times larger than the skin depth value $(\delta=0.53 \mu \mathrm{m})$ at $15 \mathrm{GHz}$. Standard photolithography was used to pattern the antenna (Fig. 3) followed by a standard wet etching process to finally fabricate the miniature antenna.

The antenna prototype was fed by a home-made SMA-type connector ( $\mathrm{V}$ glass blead connector, diameter $\varnothing=300 \mu \mathrm{m}$ ) plugged into a $20 \mathrm{~mm} \times 10 \mathrm{~mm} \times 5.5 \mathrm{~mm}$ mechanical holder. The antenna was then measured between $12 \mathrm{GHz}$ and $18 \mathrm{GHz}$ at room temperature using a StarLab near-field spherical anechoic chamber. An external dc bias electric field ranging from $E_{\text {bias }}=0 \mathrm{kV} / \mathrm{cm}$ to $E_{\text {bias }}=88 \mathrm{kV} / \mathrm{cm}$ was applied on the varactors. Note that the maximum $E_{\text {bias }}=100 \mathrm{kV} / \mathrm{cm}$ could not be achieved because of the slight over-etching of the gaps $G_{c}$ attached to the wet etching process $(17 \mu \mathrm{m}$ against $15 \mu \mathrm{m})$. The use of SHF BT 45D HV200 (SHF Communication technologies AG) broad band bias tees resulted in a measured gain lowered by $0.4 \mathrm{~dB}$.



Fig. 3. Picture by optical microscopy of the patterned antenna after the standard photolithography step.

\section{RESULTS AND DISCUSSION}

The $S_{11}$ magnitudes were measured using Ground-SignalGround (GSG) probes (Picoprobe) under $E_{\text {bias }}$ ranging from 0 to $88 \mathrm{kV} / \mathrm{cm}$. The results are plotted in Fig. 4(a). Under such experimental conditions, the antenna center frequency is tuned monotonously from 15.22 to $15.97 \mathrm{GHz}$, leading to a frequency tunability rate $T R$ equal to $4.6 \%$, computed as follows:

$$
T R=\left|\frac{\text { Freq_Ebias }=0-\text { Freq_Ebias_max }}{(\text { Freq_Ebias }=0+\text { Freq_Ebias_max }) / 2}\right| \times 100,
$$

where Freq_Ebias=0 and Freq_Ebias_max are the operating frequency values of the antenna without $E_{\text {bias }}$ and under the maximum $E_{\text {bias }}$ value, respectively. Under the various $E_{\text {bias }}$ applied on the ferroelectric varactors, the antenna remains well matched with a $-10 \mathrm{~dB}$ reflection bandwidth equal to $0.9 \mathrm{GHz}$ and $1.0 \mathrm{GHz}$ without and under $E_{\text {bias }}=88 \mathrm{kV} / \mathrm{cm}$, respectively. Comparison between the simulated and measured reflection coefficients shows a similar response at $15.2 \mathrm{GHz}$ without biasing. The slight tunability deviation between simulation (650 $\mathrm{MHz})$ and measurements $(750 \mathrm{MHz})$ is mostly attributed to the $\mathrm{KNN}$ dielectric values used in the numerical model.

Moreover the computed $T R$ value is almost four times larger than that reported by Li et al. $(T R=1.2 \%)$ using a similar topology of BST-based varactors and despite a larger biasing value used $\left(E_{\text {bias }}=195 \mathrm{kV} / \mathrm{cm}\right)$ [8]. Our result demonstrates once more the relevance of the KNN ferroelectric films for tunable devices at microwaves. The KTN-based tunable

\section{ACCEPTED MANUSCRIPT}


antenna reported by Cissé et al. exhibited a lower frequencytunability rate $(T R=1.7 \%)$ under a similar $E_{\text {bias }}$ value $\left(E_{\text {bias }}=\right.$ $85 \mathrm{kV} / \mathrm{cm}$ ) [19], [20]. However, higher frequency tunability rates $(T R=27.3 \%$ and $30.6 \%)$ have been measured by Li et al. on antennas based on MIM BST varactors [9], [10]. In these studies, the maximum dc bias electric field equaled $880 \mathrm{kV} / \mathrm{cm}$, thus about 10 times the value of the one used in the present work. It is worth noting that an accurate comparison of the tunability values required similar external static electric field. The high increase of tunability achieved through such MIM BST-based tunable antennas offers promising opportunities for the forthcoming tunable antennas based on MIM KNN varactors. Table I gives a more detailed overview of the various miniature and frequency-tunable antennas based on printed ferroelectric varactors.

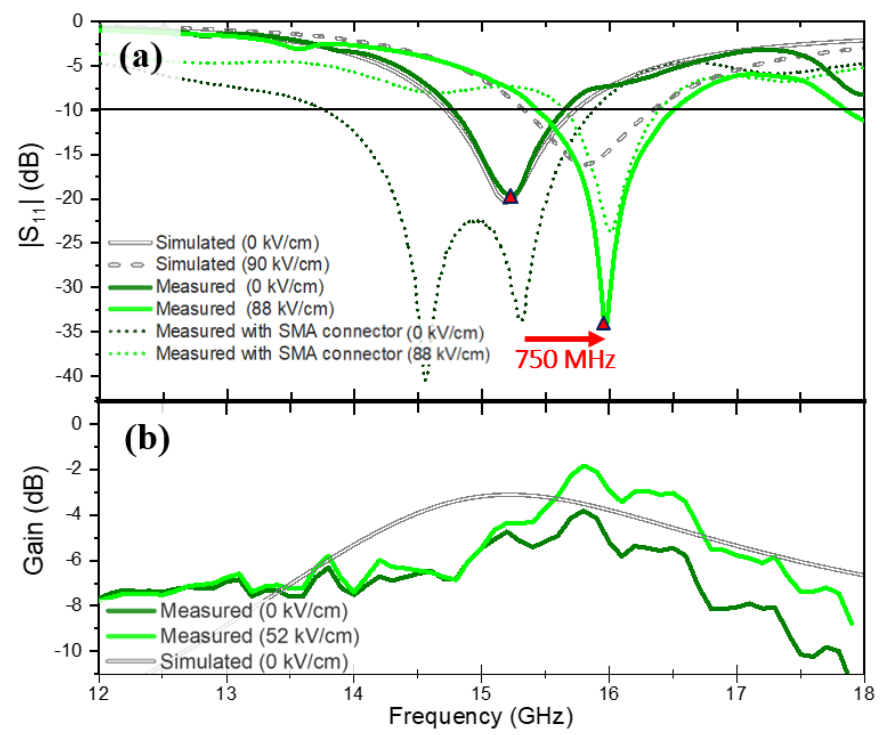

Fig. 4. Simulated and measured (a) reflection coefficient magnitudes vs. frequency under $E_{\text {bias }}$ ranging from $0 \mathrm{kV} / \mathrm{cm}$ to $88 \mathrm{kV} / \mathrm{cm}$; (b) simulated and measured gains vs. frequency without and under $E_{\text {bias }}=52 \mathrm{kV} / \mathrm{cm}$.

The tunability performance $\eta$, as defined in (2), can be used advantageously to compare the antenna prototypes of the literature [13], [26], as follows:

$$
\eta=\frac{T R}{E_{\text {bias_max }}-E_{\text {bias_min }}},
$$

where $E_{\text {bias_max }}$ and $E_{\text {bias_min }}$ are the maximum and minimum dc bias electric field values $(\mathrm{kV} / \mathrm{cm})$; and $T R$ the antenna tunability rate (\%) as defined in (1). Here the tunability performance of the antenna prototype equals $\eta=0.05$ under $E_{\max }=88 \mathrm{kV} / \mathrm{cm}$. This value is among the highest one reported in the open literature for such antennas based on ferroelectric films (see Table I). For example, BST-based varactor tunable antennas exhibit $\eta=0.03$ [13] and $\eta=0.04$ [26].

$S_{11}$ measurements performed using the SMA-type connector are also represented in Fig. 4(a) as this is the measurement setup used for the radiation patterns. It is worth noting that the response at $14.5 \mathrm{GHz}$, not appearing in the numerical simulations and in the under probes measurement, is attributed to the home-made SMA connector, much larger than the antenna itself.
The antenna gains are presented in Fig. 4(b). A maximum gain of $-2 \mathrm{~dB}$ was measured. This low value originates from the miniature size of the antenna (the dimensions of the radiating element equal $0.128 \lambda_{0} \times 0.077 \lambda_{0}$ at $15.3 \mathrm{GHz}$ ). It is worth noting that this gain value remains in the range of those reported in the literature $(-10.8 \mathrm{~dB},-3.1 \mathrm{~dB}$ and $0.5 \mathrm{~dB}$ in [8]-[10], and $-3 \mathrm{~dB}$ in [12-13] - see Table I).

The antenna radiation patterns are represented in Fig. 5. As expected, the measured radiation patterns are nearly omnidirectional [21], [22]. No significant variation is observed when the dc bias electric field is applied. The reflection coefficients and the radiation patterns were measured separately. A maximum $E_{\text {bias }}$ equal to $52 \mathrm{kV} / \mathrm{cm}$ (lower than $E_{\text {bias }}=88 \mathrm{kV} / \mathrm{cm}$ for $S_{11}$ measurements) was selected here to protect the equipments during measurements. It is worth noting that the antenna gain could be further enhanced by developing an antenna array based on the same design (e.g. [19], [20]).
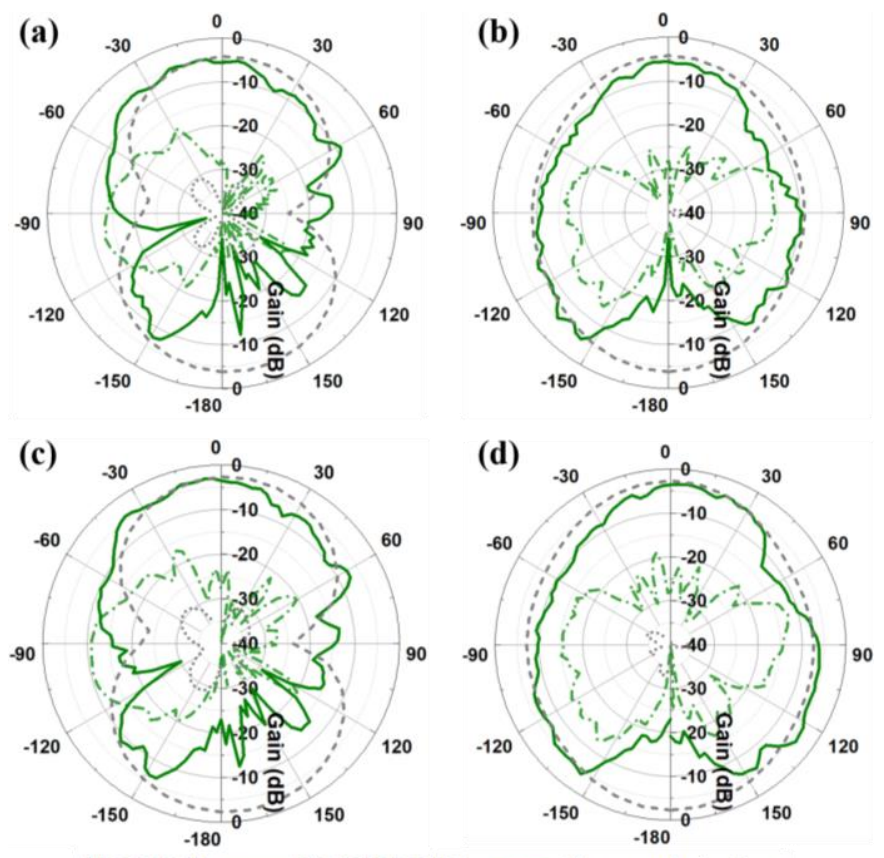

Measured: - Co-polarization

Simulated: - - Co-polarization

Cross-polarization Cross-polarization

Fig. 5. Simulated and measured radiation patterns at $15.3 \mathrm{GHz}$ without biasing: (a) E-plane and (b) H-plane; at $15.8 \mathrm{GHz}$ under $E_{\text {bias }}=52 \mathrm{kV} / \mathrm{cm}$ : (c) E-plane and (d) H-plane.

\section{CONCLUSION}

A miniature frequency-tunable slot-loop antenna loaded with KNN-based varactors was investigated at $\mathrm{Ku}$-band. The design, fabrication and experimental results were presented, discussed and compared in detail. The antenna operating frequency was tuned from 15.22 to $15.97 \mathrm{GHz}$ through a dc bias electric field applied up to $E_{\text {bias }}=88 \mathrm{kV} / \mathrm{cm}$. Its frequency tunability rate $(T R=4.6 \%)$ is among the highest value reported in the literature for such biasing conditions, demonstrating thereby that $\mathrm{KNN}$ is a competitive ferroelectric material for future tunable microwave device applications. Further improvements can be expected by increasing the biasing value and/or by changing IDC varactors by MIM varactors on such miniature and tunable microwave antennas. 


\section{REFERENCES}

[1] J. N. Sahalos and G. A. Kyriacou, Tunable Materials with Applications in Antennas and Microwaves, Morgan \& Claypool Publishers, 2019, DOI: 10.2200/S00939ED1V01Y201907ANT013.

[2] A. K. Tagantsev, V. O. Sherman, K. F. Astafiev, J. Venkatesh, and N. Setter, "Ferroelectric materials for microwave tunable applications," J. Electroceram., vol. 11, no. 1/2, pp. 5-66, 2003, DOI: 10.1023/B:JECR.0000015661.81386.e6.

[3] S. Gevorgian, Ferroelectrics in Microwave Devices, Circuits and Systems: Physics, Modelling, Fabrication and Measurements, Springer-Verlag London Limited, 2009, DOI: 10.1007/978-1-84882507-9.

[4] M. Nikfalazar, C. Kohler, A. Friederich, M. Sazegar, Y. Zheng, A. Wiens, J. Binder, and R. Jakoby, "Fully printed tunable phase shifter for L/S-band phased array application," in Proc. IEEE MTT-S IMS, Tampa, FL, USA, Jun. 1-6, 2014, pp. 1-4, DOI: 10.1109/MWSYM.2014.6848295.

[5] P. Wong and I. Hunter, "Electronically tunable filters," IEEE Microw. Mag., vol. 10, no. 6, pp. 46-54, Oct. 2009, DOI: 10.1109/MMM.2009.933593.

[6] L. Huitema, A. Ghalem, H. Wong, and A. Crunteanu, "Overview on functional materials for frequency tunable antennas," in Proc. IEEE Conf. Antenna Meas. \& Appl. (CAMA), Västerås, Sweden, Sept. 3-6, 2018, pp. 1-4, DOI: 10.1109/CAMA.2018.8530492.

[7] C. V. Varanasi, K. D. Leedy, D. H. Tomich, and G. Subramanyam, "Large area $\mathrm{Ba}_{1-\mathrm{x}} \mathrm{Sr}_{\mathrm{x}} \mathrm{TiO}_{3}$ thin films for microwave applications deposited by pulsed laser ablation," Thin Solid Films, vol. 517, no. 9, pp. 2878-2881, Mar. 2009, DOI: 10.1016/j.tsf.2008.10.123.

[8] H.-Y. Li, H.-P. Chen, S.-C. Chen, C.-H. Tai, and J.-S. Fu, "A tunable slot loop antenna using interdigitated ferroelectric varactors," in Proc. IEEE Int. Symp. Antennas Propag. (ISAP), Chicago, IL, USA, Jul. 812, 2012, pp. 1-2, DOI: 10.1109/APS.2012.6348537.

[9] H.-Y. Li, S.-C. Chen, H.-P. Chen, W.-C. Ran, and J.-S. Fu, "A frequency-reconfigurable slot loop antenna using ferroelectric MIM capacitors," IEICE Electron. Expr., vol. 10, no. 16, pp. 2013052120130521, 2013, DOI: 10.1587/elex.10.20130521.

[10] H.-Y. Li, C.-T. Yeh, J.-J. Huang, C.-W. Chang, C.-T. Yu, and J.-S. Fu, "CPW-fed frequency-reconfigurable slot-loop antenna with a tunable matching network based on ferroelectric varactors," IEEE Antennas Wirel. Propag. Lett., vol. 14, pp. 614-617, 2015, DOI: 10.1109/LAWP.2014.2375334.

[11] K. C. Pan, D. Brown, G. Subramanyam, R. Penno, H. Jiang, C. H. Zhang, M. Patterson, D. Kuhl, K. Leedy, and C. Cerny, "A reconfigurable coplanar waveguide bowtie antenna using an integrated ferroelectric thin-film varactor," Int. J. Antennas. Propag., vol. 2012, pp. 1-6, 2012, DOI: 10.1155/2012/249019.

[12] H. Jiang, M. Patterson, C. Zhang, D. Brown and G. Subramanyam, "Miniaturized and reconfigurable CPW square-ring slot antenna using thin film varactor technology," in Proc. IEEE MTT-S IMS, Baltimore, MD, USA, Jun. 5-10, 2011, pp. 1-4, DOI: 10.1109/MWSYM.2011.5972906.

[13] H. Jiang, M. Patterson, D. Brown, C. Zhang, K. C. Pan, G. Subramanyam, D. Kuhl, K. Leedy, and C. Cerny, "Miniaturized and reconfigurable CPW square-ring slot antenna loaded with ferroelectric BST thin film varactors," IEEE Trans. Antennas Propag., vol. 60, no. 7, pp. 3111-3119, Jul. 2012, DOI: 10.1109/TAP.2012.2196918.

[14] F. Zimmermann, W. Menesklou, and E. Ivers-Tiffée, "Investigation of $\mathrm{Ag}(\mathrm{Ta}, \mathrm{Nb}) \mathrm{O}_{3}$ as tunable microwave dielectric," J. Eur. Ceram. Soc. , vol. 24, no. 6, pp. 1811-1814, Jan. 2004, DOI: 10.1016/S09552219(03)00486-2.

[15] Z. Yu, C. Ang, R. Guo, and A. S. Bhalla, "Dielectric properties and tunability of $(\mathrm{Sr}, \mathrm{Bi}) \mathrm{TiO}_{3}$ with $\mathrm{MgO}$ additive," Mater. Lett., vol. 57, no. 19, pp. 2927-2931, Jun. 2003, DOI: 10.1016/S0167-577X(02)01398-8.

[16] F. Zimmermann, M. Voigts, W. Menesklou, and E. Ivers-Tiffée, " $\mathrm{Ba}_{0.6} \mathrm{Sr}_{0.4} \mathrm{TiO}_{3}$ and $\mathrm{BaZr}_{0.3} \mathrm{Ti}_{0.7} \mathrm{O}_{3}$ thick films as tunable microwave dielectrics," J. Eur. Ceram. Soc., vol. 24, no. 6, pp. 1729-1733, Jan. 2004, DOI: 10.1016/S0955-2219(03)00481-3.

[17] T. Wang, W. Jiang, R. Divan, D. Rosenmann, L. E. Ocola, Y. Peng, and G. Wang, "Novel electrically tunable microwave solenoid inductor and compact phase shifter utilizing permaloy and PZT thin films," IEEE Trans. Microw. Theory Tech., vol. 65, no. 10, pp. 3569-3577, Oct. 2017, DOI: 10.1109/TMTT.2017.2731765.

[18] Q. Simon, Y. Corredores, X. Castel, R. Benzerga, R. Sauleau, K. Mahdjoubi, A. Le Febvrier, S. Députier, M. Guilloux-Viry,
L. Zhang, P. Laurent, and G. Tanné, "Highly tunable microwave stub resonator on ferroelectric $\mathrm{KTa}_{0.5} \mathrm{Nb}_{0.5} \mathrm{O}_{3}$ thin film," Appl. Phys. Lett., vol. 99, no. 9, p. 092904, Aug. 2011, DOI: 10.1063/1.3626040.

[19] F. Cissé, "Dispositifs hyperfréquences et antennes périodiques reconfigurables à base de films minces ferroélectriques des systèmes KTN-KNN," Ph.D. Dissertation, Univ. Rennes 1, Rennes, France, Jul. 2017.

[20] F. Cissé, X.Castel, R. Sauleau, R. Benzerga, S. Députier, V. Bouquet, and M. Guilloux-Viry, "Tunable leaky-wave antenna based on ferroelectric $\mathrm{KTa}_{0.5} \mathrm{Nb}_{0.5} \mathrm{O}_{3}$ thin film," in Proc. E-MRS Spring Meeting, Nice, France, May 27-31, 2019.

[21] Y. Saito, H. Takao, T. Tani, T. Nonoyama, K. Takatori, T. Homma, T. Nagaya, and M. Nakamura, "Lead-free piezoceramics," Nature, vol. 432, no. 7013, pp. 84-87, Nov. 2004, DOI: 10.1038/nature03028.

[22] G. Shirane, R. Newnham, and R. Pepinsky, "Dielectric properties and phase transitions of $\mathrm{NaNbO}_{3}$ and $(\mathrm{Na}, \mathrm{K}) \mathrm{NbO}_{3}$," Phys. Rev., vol. 96, no. 3, pp. 581-588, Nov. 1954, DOI: 10.1103/PhysRev.96.581.

[23] B. Aspe, F. Cissé, X. Castel, V. Demange, S. Députier, S. Ollivier, V. Bouquet, L. Joanny, R. Sauleau, and M. Guilloux-Viry, " $\mathrm{K}_{\mathrm{x}} \mathrm{Na}_{1-\mathrm{x}} \mathrm{NbO}_{3}$ perovskite thin films grown by pulsed laser deposition on R-plane sapphire for tunable microwave devices," J Mater Sci, vol. 53, no. 18, pp. $13042-13052$, Sept. 2018, DOI: 10.1007/s10853-0182593-9.

[24] B. Aspe, X. Castel, V. Demange, D. Passerieux, M. A. Pinault-Thaury, F. Jomard, S. Députier, D. Cros, V. Madrangeas, V. Bouquet, R. Sauleau and M. Guilloux-Viry, "Enhanced tunability and temperaturedependent dielectric characteristics at microwaves of $\mathrm{K}_{0.5} \mathrm{Na}_{0.5} \mathrm{NbO}_{3}$ thin films epitaxially grown on (100)MgO substrates," J. Alloys Compd., vol. 856, pp. 158138, 2020, DOI: 10.1016/j.jallcom.2020.158138

[25] F. Cissé, X. Castel, R. Sauleau, R. Benzerga, S. Députier, V. Bouquet and M. Guillloux-Viry, "A twofold approach in loss reduction of $\mathrm{KTa}_{0.5} \mathrm{Nb}_{0.5} \mathrm{O}_{3}$ ferroelectric layers for low-loss tunable devices at microwaves," IEEE Trans. Ultrason. Ferroelectr. Freq. Contr., vol. 65, no. 4, pp. 665-671, Apr. 2018, DOI: 10.1109/TUFFC.2018.2795108.

[26] H. V. Nguyen, R. Benzerga, C. Borderon, C. Delaveaud, A. Sharaiha, R. Renoud, C. Le Paven, S. Pavy, K. Nadaud, and H. Gundel., "Miniaturized and reconfigurable notch antenna based on a BST ferroelectric thin film," Mater. Res. Bull., vol. 67, pp. 255-260, Jul. 2015, DOI: 10.1016/j.materresbull.2015.02.034.

[27] C. R. White and G. M. Rebeiz, "Single- and dual-polarized tunable slotring antennas," IEEE Trans. Antennas Propag., vol. 57, no. 1, pp. 1926, Jan. 2009, DOI: 10.1109/TAP.2008.2009664.

[28] P.-L. Chi, R. Waterhouse, and T. Itoh, "Compact and tunable slot-loop antenna," IEEE Trans. Antennas Propag., vol. 59, no. 4, pp. 13941397, Apr. 2011, DOI: 10.1109/TAP.2011.2109687. 